\title{
O AVANÇO DA CARBONATAÇÃO APÓS 20 ANOS DE ABANDONO DE UMA EDIFICAÇÃO INACABADA EM CONCRETO ARMADO
}

\author{
PILZ, SILVIO E. \\ Engenheiro Civil \\ Unochapecó \\ SC; Brasil \\ flaviamarinap@unochapeco.edu.br \\ IGNAULIN, KARINE
Engenheira Civil
Unochapecó
SC; Brasil
karineignaulin@unochapeco.edu.br \\ COSTELLA, MARCELO F. \\ Engenheiro Civil \\ Unochapecó \\ SC; Brasil \\ costella@unochapeco.edu.br
}

\author{
COSTELLA, MONIKE M. \\ Engenheira Civil \\ Unochapecó \\ $\mathrm{SC}$; Brasil \\ monike@unochapeco.edu.br
}

\author{
SLOMSKI, LAURA F. \\ Engenheira Civil \\ Unochapecó \\ SC; Brasil \\ lauraslomski@unochapeco.edu.br
}

\author{
BATISTON, EDUARDO R. \\ Engenheiro Civil \\ Unochapecó \\ $\mathrm{SC}$; Brasil \\ erbatiston@unochapeco.edu.br
}

\section{RESUMO}

A retomada de uma edificação abandonada necessita de critérios que quantifiquem o grau de degradação, bem como estimem a vida útil da estrutura. A manutenção não é realizada em edificações abandonadas e com isso os materiais ficam expostos tendo o seu processo de degradação acelerado. O objetivo desta pesquisa é medir o avanço da carbonatação em diferentes condições de exposição de uma edificação inacabada em concreto armado no oeste de Santa Catarina com mais de 20 anos de paralisação da obra. A metodologia consistiu em selecionar elementos estruturais que apresentassem boas condições visuais dos elementos estruturais com diferentes condições de conservação como: exposição solar, com e sem reboco, faces internas e externas, elementos enterrados e expostos, úmidos e ventilados. A realização do teste de carbonatação nas amostras foi realizado com fenolftaleína. $\mathrm{O}$ resultado mostrou que as maiores espessuras carbonatadas foram encontradas na parte interna na edificação indicando que havia superfícies úmidas por um extenso período. Os elementos estruturais revestidos com argamassa apresentaram um retrocesso de carbonatação, na média 50\% menor, resultando um aumento de 4 anos da vida útil, demonstrando que os revestimentos de argamassa devem ser considerados nas estimativas de vida útil das estruturas. Um ponto de destaque foi que o avanço da carbonatação na viga baldrame enterrada foi praticamente nulo, comprovando que o solo seco e a baixa oxigenação contribuem para o aumento da vida útil da estrutura.

Palavras-chave: carbonatação, edificação abandonada, mecanismos de degradação, vida útil.

\section{ABSTRACT}

The restoration of an abandoned building needs criteria that quantify the degree of degradation as well as estimate the useful life of the structure. Maintenance is not performed in abandoned buildings, and thus the materials are exposed, and their process of degradation accelerated. The objective of this research is to measure the advancement of carbonation under different exposure conditions of an unfinished reinforced concrete building in western Santa Catarina with over 20 years of the work stoppage. The methodology consisted of selecting structural elements that presented good visual conditions with different conservation conditions such as sun exposure, with and without mortar coating, internal and external faces, buried and exposed structure, wet and ventilated. The carbonation test was performed with phenolphthalein. The result showed that the largest carbonated thicknesses were found inside the building, indicating that there were damp surfaces for an extended period. The mortar-coated structural elements had a $50 \%$ lower average carbonation retracement, resulting in a 4-year increase in service life, demonstrating that mortar coatings should be considered in the structural lifetime estimates. The important point was that the carbonation 
advance in the buried foundation beam was practically nil, proving that the dry soil contributes to the increase of the useful life of the structure.

Keywords: carbonation, abandoned building, degradation mechanisms, useful life.

\section{INTRODUÇÃO}

Construções antigas e abandonadas tendem a sofrer degradações devido à exposição às intempéries, inexistência de manutenções ou por ações humanas. Estas estruturas precisam passar por uma avaliação econômica da continuidade, reparos ou em casos extremos a demolição da edificação abandonada. Para isso devem ser realizadas avaliações técnicas para estudar o grau de degradação da estrutura e a previsibilidade da vida útil. Através destas avaliações podese verificar a possibilidade da utilização total da estrutura em relação às funções a qual ela foi projetada, garantindo assim a segurança do local (BERTOLINI, 2010).

O concreto nas idades iniciais tem um pH elevado girando em torno de 12,5, permitindo a formação de uma camada superficial de dióxidos estáveis sobre as armaduras, capaz de protegê-las contra corrosão, obtendo assim uma armadura denominada passivada (ARAÚJO, 2014). Mehta e Monteiro (2008) enfatizam que esta camada superficial (filme protetor que recobre o aço), é considerada estável desde que o pH se mantenha em valores acima de 11,5.

Complementado a citação de Kazmierczak (1995) no que diz respeito a velocidade e a profundidade dependerem de fatores do meio ambiente, o fenômeno da carbonatação está associado as reações químicas da interação dos elementos presentes na atmosfera, como o $\mathrm{CO} 2$ (gás carbônico) com os produtos da hidratação do cimento (hidróxido de cálcio) (CUNHA; HELENE, 2001). A resultante da ação do dióxido de carbono $\left(\mathrm{CO}_{2}\right)$, formando o carbonato de cálcio $\left(\mathrm{CACO}_{3}\right)$, provoca redução da alcalinidade do concreto (PAPADAKIS et al., 1991; SOUZA; RIPPER, 1998).

Como as edificações abandonadas normalmente não passam por processos de manutenção, os materiais acabam ficando expostos fazendo com que as edificações sofram degradação por fatores do tempo como variações de temperatura, umidade e presença de agentes agressivos (ISMAIL; YEW; MUHAMMAD, 2015), que ocasiona a despassivação da armadura por carbonatação. Portanto, este trabalho tem por objetivo medir o avanço da carbonatação em diferentes condições de exposição de uma edificação inacabada em concreto armado no oeste de Santa Catarina com mais de 20 anos de paralisação da obra.

\section{MÉTODO DE PESQUISA}

A documentação era restrita, por isso o método de pesquisa precisou ser moldado em função das informações técnicas que estavam acessíveis. Assim, os procedimentos metodológicos adotados estão representados na Figura 1.

Figura 1 - Fluxograma de procedimentos adotados

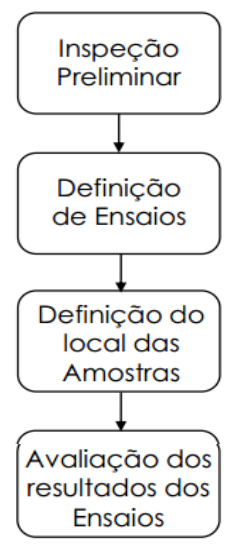

Fonte: elaborada pelos autores

A inspeção preliminar foi realizada na edificação (Figura 2) que obteve o alvará em 1998, porém nunca chegou a ser concluída, ficando exposta a intempéries sem os devidos acabamentos e as manutenções adequadas, até o momento da coleta de dados para análise neste trabalho. O período de construção da obra foi de 1998 a 2001 . A obra foi constituída com estrutura de concreto armado moldado in loco com fechamento de alvenaria de vedação, com área total construída 
de 4.947,95 $\mathrm{m}^{2}$ composta de 5 pavimentos tipo, cobertura com projeção de piscina, garagem no subsolo e térreo com pé direito duplo. A obra não dispõe de projetos em arquivos digitais, somente documentação em papel.

Para a contextualização dos locais, foram utilizadas as plantas de formas originais. Esta obra foi projetada utilizando concreto dosado em central sendo que a resistência característica do concreto utilizada em projeto foi de 15 Mpa. Não foram realizados ensaios de controle de resistência do concreto na época pela construtora. Parte da estrutura apresentava revestimentos em argamassa de cimento cal e areia e parte da estrutura encontra-se exposta.

Figura 2 - Vista Frontal e Lateral (Sul)

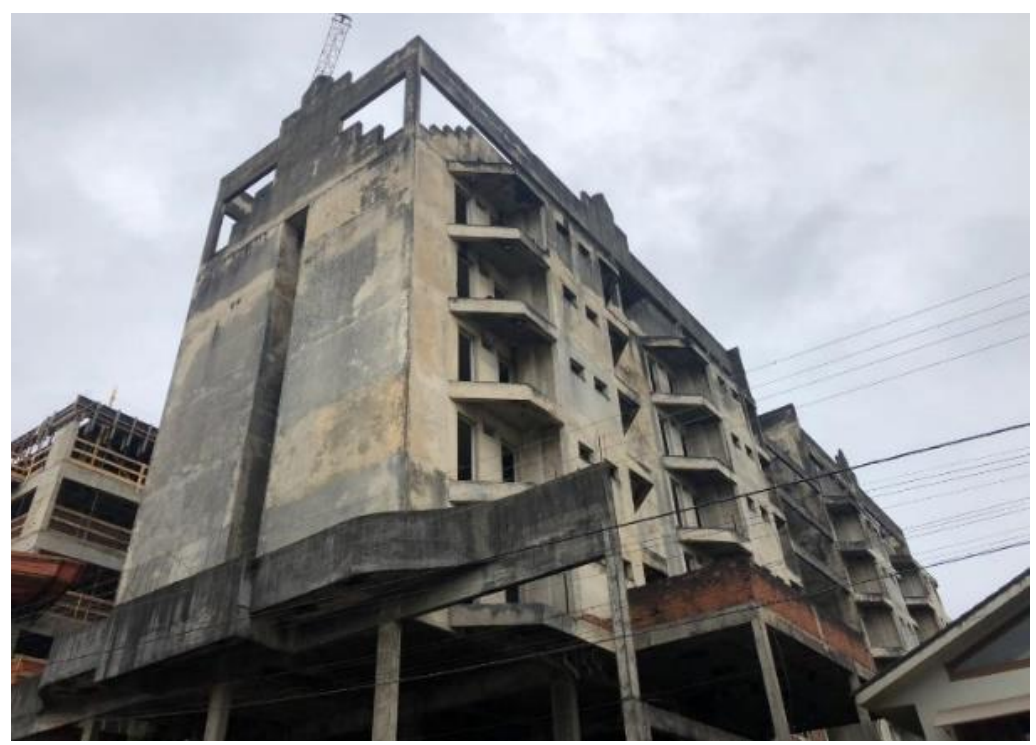

Fonte: elaborada pelos autores

Os ensaios definidos foram, para esse artigo, o de avanço da carbonatação do concreto. O ensaio de carbonatação foi realizado a partir do uso de uma solução alcoólica de fenolftaleína aplicado em todos os elementos definidos anteriormente, nos furos nas peças obtidas pelas extrações de amostras e nos próprios testemunhos. A solução era aspergida nas amostras, logo após sua extração. A coloração violeta indicava que a amostra não estava carbonatada, porém a ausência estava relacionada a região a qual sofria o processo de carbonatação (SAHUINCO, 2011). A partir disso, foi realizada a medida da profundidade de carbonatação em cada amostra dos elementos escolhidos (FERREIRA, 2000). Após, foi realizado o cálculo da velocidade da carbonatação em função da resistência do concreto, segundo as equações 01 e 02 , adotando o fck de projeto de $15 \mathrm{MPa}$ e a estimativa da resistência atual do concreto em função da idade de $25 \mathrm{MPa}$ para o tempo de 20 anos (ANDRADE PEDRIX, 1992):

$$
\begin{aligned}
& K_{\mathrm{CO2}}=6,7882-0,1132 f_{c k} \\
& e_{\mathrm{CO2}}=K_{\mathrm{CO2} 2} \sqrt{t}
\end{aligned}
$$

Onde:

$\mathrm{K}_{\mathrm{CO} 2}=$ Coeficiente de carbonatação $\left(\mathrm{m} / \mathrm{s}^{1 / 2}\right)$;

$\mathrm{F}_{\mathrm{ck}}=$ Resistência característica do concreto (Mpa);

$\mathrm{e}_{\mathrm{CO} 2}=$ espessura de carbonatação $(\mathrm{m})$;

$\mathrm{t}=$ tempo estimado para a carbonatação atingir a armadura (anos);

Foi realizada a definição do local das amostras por meio da demarcação dos pontos para obtenção de amostras e testemunhos, considerando a acessibilidade aos ensaios, diferentes condições de exposição da estrutura às intempéries e relatório fotográfico. No subsolo retirou-se a amostra entre P16 - P28 (viga 16 - 15X35), conforme Figura 3, da viga de baldrame encontrava-se enterrada. 


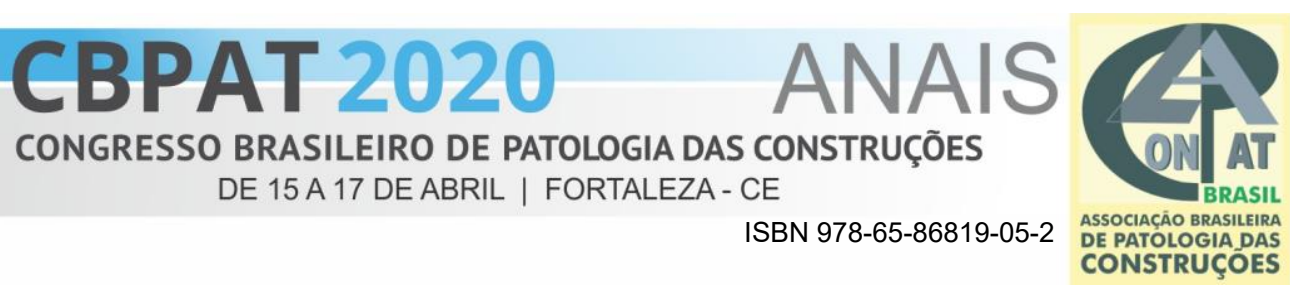

Figura 3 - Locais de identificação da amostra no subsolo

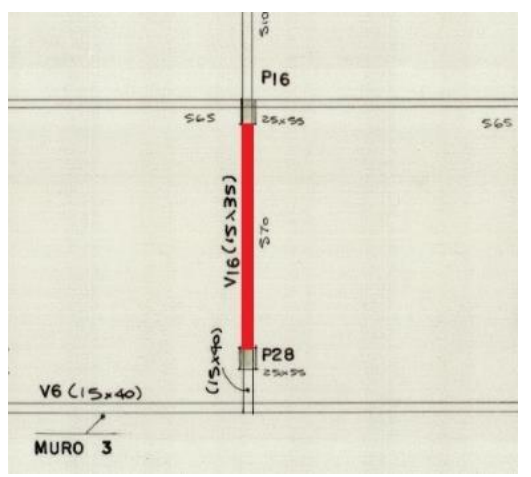

Fonte: elaborada pelos autores

No pavimento térreo as amostras foram escolhidas em função da fácil acessibilidade, posição solar e condições visuais do elemento, resultando nas vigas entre os pilares P14 - P15 (viga 103 - 15x15), P15 - P27(viga 119 - 15x50), P 29 P41 (viga 122 - 15x60), P 29 - P30 (viga 105 -15x55), P 31 - P32 (viga 203 - 15x30), P 55 - 56 (viga 205 - 15x30), conforme Figura 4.

Figura 4 - Locais de identificação da amostra no térreo
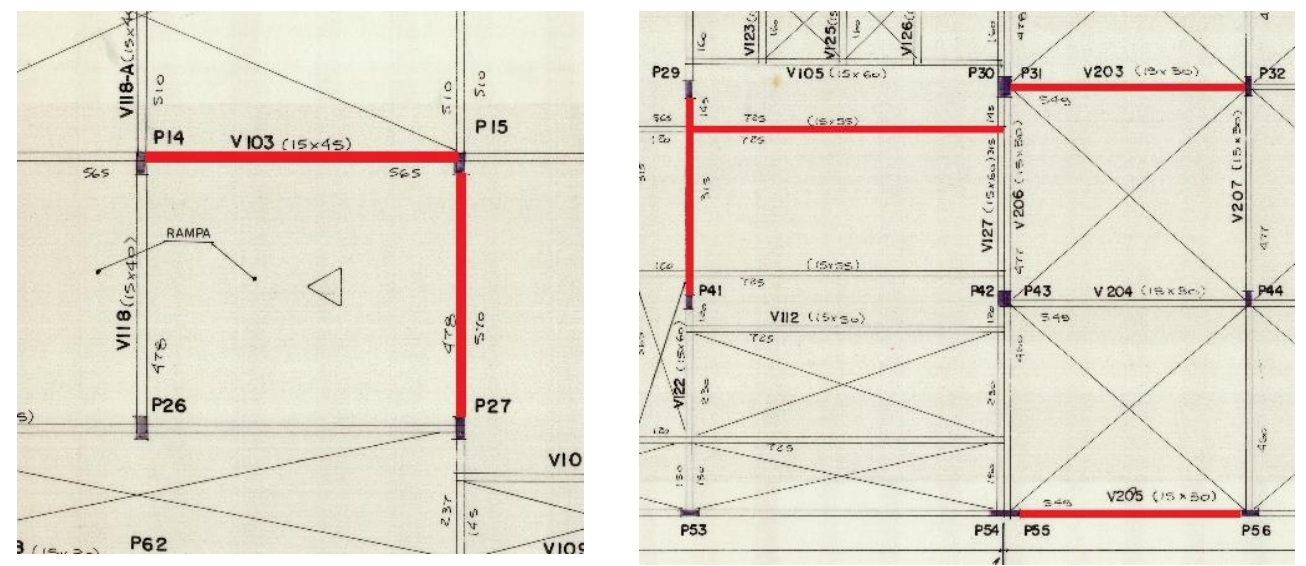

Fonte: elaborada pelos autores

A escolha das amostras no primeiro pavimento estavam posicionadas na fachada e outras internamente à edificação, os quais não recebiam exposição solar, sendo os pilares P13 -P25 (viga 313 - 15x45), P25 - P26 (viga 304 - 15x45), P33 P34 (viga 403 - 15x45) e P 45 - 46 (viga 404 - 15x55), conforme a Figura 5.

Figura 5 - Locais de identificação da amostra no primeiro pavimento
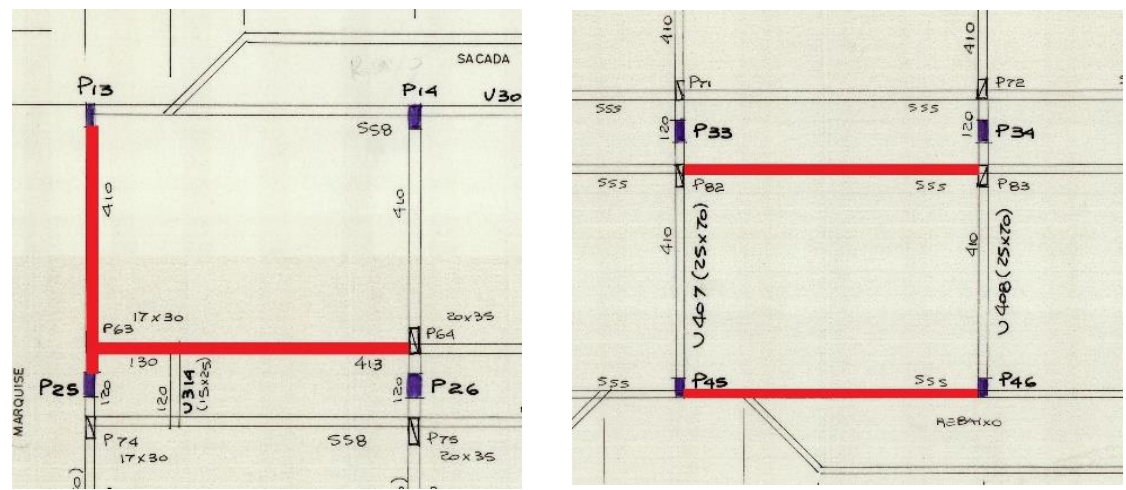

Fonte: elaborada pelos autores 
No pavimento tipo 2, as amostras escolhidas foram das vigas da sacada, sendo uma delas rebocada e a outra não, para posterior efeitos de comparação, conforme Figura 6.

Figura 6 - Locais de identificação da amostra no segundo pavimento

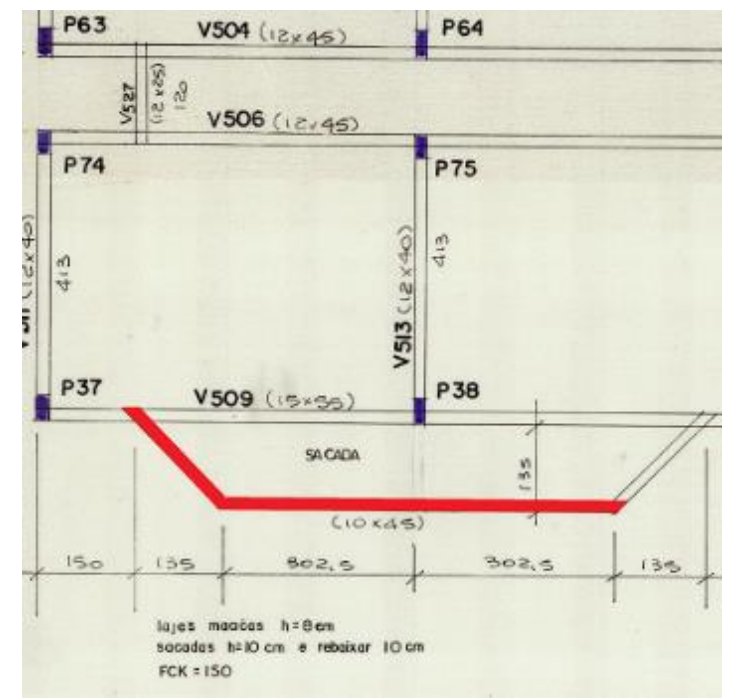

Fonte: elaborada pelos autores

A avaliação dos resultados dos ensaios considerou uma apresentação da inspeção visual com registro fotográfica, a medida da profundidade de carbonatação em cada local conforme as condições de exposição e a comparação com a estimativa do avanço da carbonatação em função da resistência do concreto.

\section{APRESENTAÇÃO E DISCUSSÃO DOS RESULTADOS}

Foram constadas diversas manifestações patológicas no momento da inspeção visual preliminar, conforme Figura 7, que comprovaram a degradação da estrutura, tais como, nichos de concretagem, armadura exposta, desplacamento do concreto e grande umidade. Também foi constatado que os elementos mais afetados pelas manifestações patológicas foram as lajes as quais $70 \%$ encontravam-se com intensa presença de umidade e desgaste superficial. No entanto, para as vigas e pilares apenas 10\% do total apresentava algum sintoma visível de manifestação patológica.

Figura 7 - Nicho de concretagem, corrosão de armaduras, presença de mofo, respectivamente
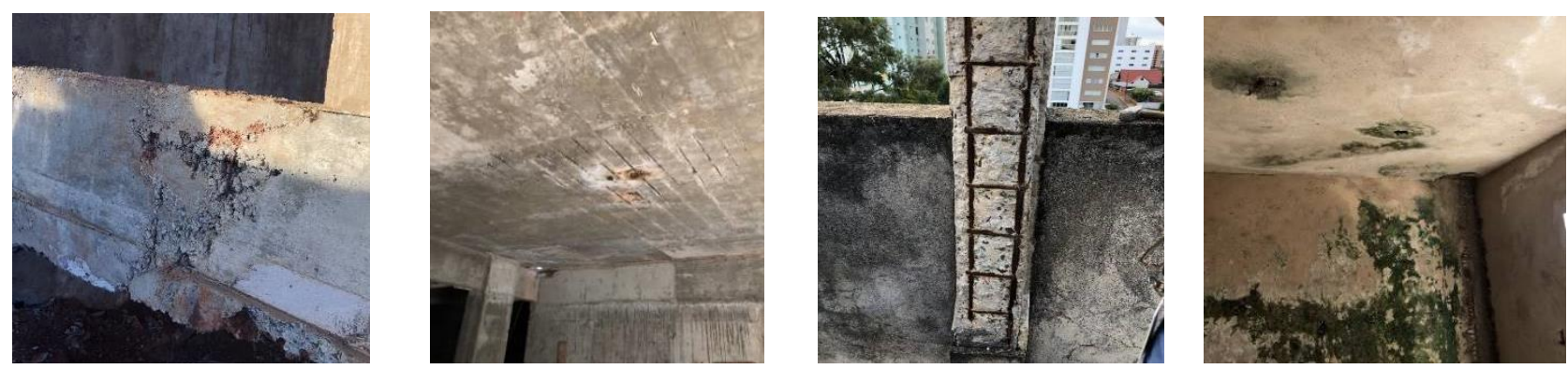

Fonte: elaborada pelos autores

Conforme mostrado a seguir na Tabela 1 , as maiores espessuras carbonatadas encontravam-se internamente na edificação. Nas lajes, a constante presença de umidade aliada à baixa incidência dos raios solares foram fatores que contribuíram para o avanço da carbonatação, conforme corrobora Zenato (2018). Para demostrar este fato comparou-se duas vigas no mesmo pavimento, uma interna (viga 203) e outra externa (viga 205) a edificação. A diferença do avanço da carbonatação foi de $27 \mathrm{~mm}$ a mais para a viga interna, a qual teve a maior espessura carbonatada de todas as vigas ensaiadas. 
Tabela 1 - Dados obtidos após ensaio de carbonatação

\begin{tabular}{|c|l|c|c|}
\hline \multicolumn{2}{|c|}{ Identificação } & Posição na edificação & Carbonatação (mm) \\
\hline Subsolo & Viga 16 (P16 - P28) & Enterrada & Não Carbonatado \\
\hline \multirow{4}{*}{ Térreo } & Viga 103 (P14 - P15) & Interna & 42,43 \\
\cline { 2 - 4 } & Viga 119 (P15 - P27) & Interna & 36,50 \\
\cline { 2 - 4 } & Viga 122 (P29 - P41) & Externa & 44,56 \\
\cline { 2 - 4 } & Viga 105 (P29 - P30) & Externa & 48,62 \\
\cline { 2 - 4 } & Viga 203 (P31 - P32) & Interna & 71,48 \\
\cline { 2 - 4 } & Viga 205 (P55 - P56) & Externa & 44,49 \\
\hline \multirow{4}{*}{$\mathbf{1}^{\mathbf{o}}$ pav. } & Viga 313 (P13 - P25) & Externa & 42,98 \\
\cline { 2 - 4 } & Viga 304 (P25 - P26) & Interna & 54,92 \\
\cline { 2 - 4 } & Viga 403 (P33 - P34) & Interna & 70,07 \\
\cline { 2 - 4 } & Viga 404 (P45 - P46) & Externa & 44,10 \\
\hline \multirow{2}{*}{$\mathbf{2}^{\mathbf{o}}$ pav. } & Viga sacada sem reboco & Externa & 47,00 \\
\cline { 2 - 4 } & Viga sacada com reboco & Externa & 31,23 \\
\hline
\end{tabular}

Fonte: Elaborada pelos autores

Através do ensaio realizado na viga de baldrame no subsolo, observou-se que o avanço da carbonatação foi praticamente nulo, o que demonstra que o solo seco em contato com o concreto diminui o avanço da frente de carbonatação (Figura 8).

Figura 8 - Viga de baldrame após a aspersão da solução de fenolftaleína no local da extração da amostra

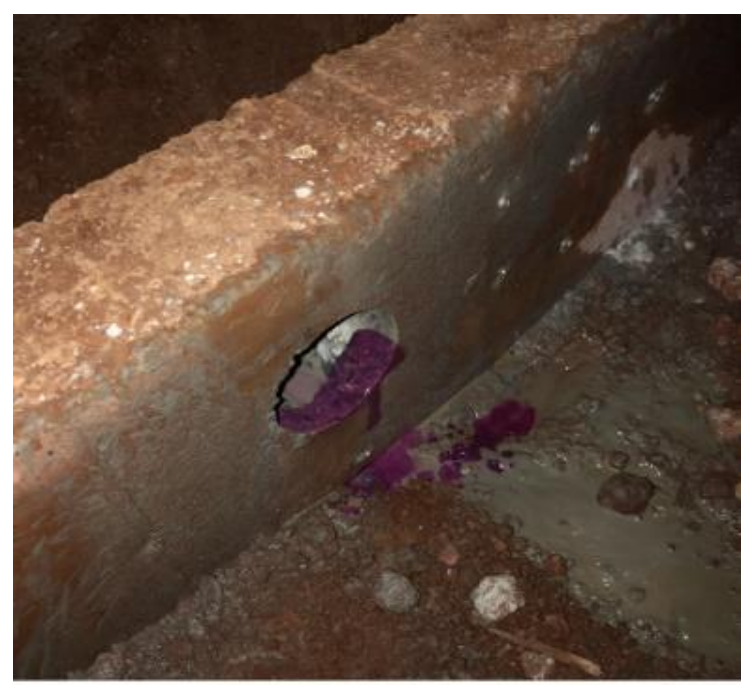

Fonte: elaborada pelos autores

$\mathrm{Na}$ análise das demais vigas, notou-se que a maior espessura carbonatada, obteve um resultado da resistência à compressão maior, conforme dados apresentados na Tabela 1. Esta ocorrência pode ser explicada, provavelmente devido ao processo de cura durante a execução. Quando o processo é incompleto ou insuficiente o concreto permanece com maiores poros capilares, contribuindo para a penetração dos agentes que favorecendo o avanço da carbonatação.

Analisou-se a viga da fachada do $2^{\circ}$ pavimento, a qual ficava exposta aos raios solares e verificou-se que tinha sido executada com e sem reboco. A parte da viga sem a camada de reboco apresentou um avanço de $67 \%$ a mais quando comparada com a parte da viga com reboco, conforme Figura 9. Assim, conclui-se que o reboco contribuiu para que a carbonatação não avançasse. 
Figura 9 - Amostras após a aspersão da solução de fenolftaleína

\begin{tabular}{|c|c|c|c|}
\hline \multicolumn{2}{|c|}{ Viga Fachada sem Reboco } & \multicolumn{2}{c|}{ Viga Fachada com Reboco } \\
\hline Externo & Interno & Externo & Interno \\
\hline & & & \\
\hline & & & \\
\hline & & & \\
\hline
\end{tabular}

Fonte: elaborada pelos autores

Para calcular a velocidade de carbonatação do concreto, segundo as equações 01 e 02, adotando um fck de projeto de 15 $\mathrm{MPa}$ encontrou-se um coeficiente de carbonatação $\left(\mathrm{K}_{\mathrm{co} 2}\right)$ igual a 5,0917 mm/ano, considerando o passar de 20 anos que a estrutura encontrava-se em abandono, determinou-se então a profundidade de carbonatação resultante de $22,77 \mathrm{~mm}$. Para a resistência de $25 \mathrm{MPa}$, utilizando essa resistência para os cálculos novamente, resulta em um coeficiente de 3,9607 mm/ano e uma profundidade de carbonatação de 17,71 mm, conforme cálculos apresentados no Figura 10.

Figura 10 - Estimativa em anos do avanço da profundidade de carbonatação

\begin{tabular}{|c|c|}
\hline $\mathrm{f}_{\mathrm{ck}}$ adotado em projeto & Média $f_{\text {ck }}$ estimado no ensaio de compressão \\
\hline $\begin{array}{l}f_{c k}=15 \mathrm{MPa} \\
K_{\mathrm{Co2}}=6,7882-0,1332 f_{c k} \\
K_{c o 2}=5,0917 \mathrm{~mm} / \text { ano }\end{array}$ & $\begin{array}{l}f_{c k}=25 \mathrm{MPa} \\
K_{\mathrm{Co2}}=6,7882-0,1332 f_{c k} \\
K_{\mathrm{co2}}=3,9607 \mathrm{~mm} / \mathrm{ano}\end{array}$ \\
\hline $\begin{array}{l}t=20 \text { anos } \\
\theta_{\mathrm{CO} 2}=K_{\mathrm{CO} 2} \sqrt{t} \\
\theta_{\mathrm{CO} 2}=22,77 \mathrm{~mm}\end{array}$ & $\begin{array}{l}t=20 \text { anos } \\
e_{\mathrm{CO2}}=K_{\mathrm{CO2}} \sqrt{t} \\
e_{\mathrm{CO} 2}=17,71 \mathrm{~mm}\end{array}$ \\
\hline
\end{tabular}

Fonte: elaborada pelos autores

\section{CONCLUSÃO}

Estruturas em abandono necessitam avaliações para verificar o grau de degradação e avaliação da segurança estrutural. Neste trabalho observou-se que os elementos estruturais revestidos com argamassa tiveram a velocidade de carbonatação, na média, 50\% menor, resultando a uma estimativa de aumento de, aproximadamente, 4 anos da vida útil. Este dado demostra que os revestimentos de argamassa podem e devem ser considerados nas estimativas de vida útil das estruturas. Outro fato importante é que o solo também contribuiu para a diminuição da frente de carbonatação se tornando um elemento pouco considerado.

Observou-se também que a umidade acelerou o avanço da carbonatação, pois possibilitou a dissolução do hidróxido de cálcio e facilita a difusão do dióxido de carbono nos poros capilares do concreto. Os elementos que neste trabalho tiveram um contato maior com a umidade apresentaram um maior avanço da carbonatação.

De maneira geral vários elementos apresentaram a profundidade de carbonatação elevada e consequente aumento da resistência do concreto, mas sem indicar o início de corrosão das armaduras. Outro ponto de destaque foi na viga baldrame onde a carbonatação foi praticamente nula comprovando que o solo seco e a baixa oxigenação contribuem para o aumento da vida útil da estrutura. 


\section{AGRADECIMENTOS}

Agradecemos ao Ricardo Caraça, da empresa Terrax Obras e Terraplenagem, pela disponibilização dos funcionários para realização dos ensaios.

\section{REFERÊNCIAS}

ANDRADE PERDRIX, C. Manual para diagnóstico de obras deterioradas por corrosão de armaduras. Tradução e adaptação Antonio Carmona e Paulo Helene. São Paulo: Pini, 1992.

ARAUjO, J. A. Curso de Concreto Armado. 04. ed. Rio Grande: Dunas, 2014.

BERTOLINI, L. R. L. Materiais de Construção: patologia, reabilitação, prevenção. São Paulo: Oficina de Textos, 2010.

CUNHA, A. C. Q. da; HELENE, P. R. Despassivação das Armaduras de Concreto por Ação da Carbonatação. São Paulo: Boletim Técnico da Escola Politécnica, 2001.

FERREIRA, R. M. Avaliação dos Ensaios de Durabilidade do Betão. 2000. 246 f. Dissertação (Mestrado) - Curso de Engenharia Civil, Universidade do Minho, Guimarães, 2000.

HELENE, P. R. L. Vida útil das estruturas de concreto. In: Congresso ibero-americano de patologia das construções, v.1, 4.,1997, Porto Alegre, RS- Brasil. 1997. p. 1-30.

ISMAIL, M; YEW, C. K.; MUHAMMAD, B. Life-span prediction of abandoned reinforced concrete residential buildings, Construction and Building Materials, v. 112, p. 1059-1065, jun. 2016.

KAZMIERCZAK, C. S. Contribuição para a análise da eficiência de películas aplicadas sobre estruturas de concreto armado com o objetivo de proteção contra a carbonatação. 1995. Tese (Doutorado) - Escola Politécnica, Universidade de São Paulo, 1995.

MEHTA, P. K.; MONTEIRO, P. J. M., Concreto: microestrutura, propriedades e materiais. 3.ed. São Paulo, IBRACON, 2008.

PAPADAKIS, V. G.; VAYENAS, C. G.; FARDIS, M. N. Physical and Chemical Characteristics Affecting the Durability of Concrete. ACI Materials Journal, v. 8, n. 2, mar-abr 1991.

SAHUÍNCO, M. H. C. Utilização de métodos não destrutivos e semi-destrutivos na avaliação de pontes de concreto. Dissertação (Mestrado) - Curso de Engenharia Civil, Escola Politécnica de São Paulo, São Paulo, 2011.

SOUZA, V. C. M; RIPPER, T. Patologia, Recuperação e Reforço de Estruturas de Concreto. São Paulo: PINI, 1998.

ZENATO, C. et al. Determinação de vida útil residual de estrutura de concreto de edifício residencial multifamiliar. Concreto e Construções, v. 91, p. 51-55, Jul-Set 2018. 